\title{
Technology Analysis and the Need of a Value Framework
}

doi:10.2478/mape-2021-0038

Date of submission to the Editor: $05 / 2021$

Date of acceptance by the Editor: 06/2021

Agnieszka Lekka-Kowalik

ORCID ID: 0000-0002-4834-318X

John Paul II Catholic University of Lublin, Poland
MAPE 2021, volume 4, issue 1, pp. 421-430

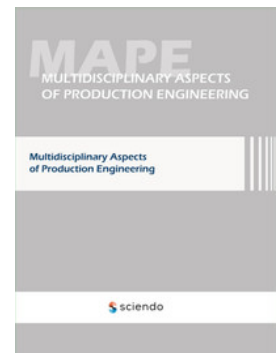

\section{THE VALUE-LADENNESS OF TECHNOLOGY}

In the discussion on the relationship between technology and values, the term "value" other than technological, economic, and (arguably) aesthetic. There exist arguments for the value-neutrality of technology in this sense: technological artifacts are not agents, so one cannot predicate values of them; these artifacts can be used for good and bad ends, so in themselves they are neutral; the same processes occur in artifacts seen as 'good' as in those seen as 'bad'; one should distinguish technological artifacts in themselves from a context in which they function - they may be treated in the same way as natural phenomena which bring benefits or harms, depending on a situation in which they occur. There are good reasons to claim that none of these arguments work (Lizut 2014). However, from that one cannot infer that the thesis of valueneutrality of technology is false. We need then to develop positive arguments for the value-ladenness of technology. Four of them will be here considered: (1) restructuration of our material, social, and symbolic world by technology; (2) embeddement of values in a technological artifact's material structure; (3) politics of artifacts; (4) increasing the net utility gained from activities performed with technologies. Before considering the listed arguments we need however to notice that contemporary technologies are not merely material objects. Perhaps relatively simple tools, such as a hammer, may be seen as such objects. Yet, contemporary technological artifacts are systems consisting of things and institutions and therefore their boundaries are difficult to define. You can show the size of the hammer, you can put the hammer in its place. The boundaries of the air conditioning unit are not so obvious anymore. This device has a case, impeller, filters, etc. However, you will not have yet air conditioning, if a cord with a plug is not attached to it, the plug is not stuck in the electrical socket connected to the box ... Where then is the end of a technical device called air conditioning? Moreover, if we create a system that consists exactly of the same material elements, but there will be no institution called a power plant, we will not be the owners of the air-conditioning device. Thus, a technological artifact is a system 
that consists of material objects but also of institutions that guarantee its correct and intended functioning.

Ad 1. Contemporary technological artifacts certainly reshape our material and social world, for, in order to have them function, we need to „adjust” the world to their „requirements”. A car needs roads, petrol stations, maintenance services, and many other things. This means that introducing a car into our life-space caused not only changes in nature (such as cutting trees to build a highway) but also changes in a job market, industry, law, education offer, architecture, and many other domains of life. Technology causes also conceptual restructuration. Abraham Maslow said that "it is tempting, if the only tool you have is a hammer, to treat everything as if it were a nail $(1966,15)$. Postman added: „To a person with a pencil, everything looks like a sentence. To a person with a TV camera, everything looks like an image. To a person with a computer, everything looks like data (Postman, 1998). Postman argues that technologies are not just tools, but they are metaphors through which we conceptualize reality: „every technology has a philosophy which is given expression in how the technology makes people use their minds, in what it makes us do with our bodies, in how it codifies the world, in which of our senses it amplifies, in which of our emotional and intellectual tendencies it disregards" (Postman, 1998.) We see how medical technologies redefine what "good medical practice” or „adequate health care” is. Moreover, technology seems to reshapes our understanding of values (LekkaKowalik, 2005). Discussions concerning e-democracy, e-friendship, e-privacy, e-security testify to that claim.

Ad 2. The situation is, however, even more complicated. For technological artifacts have values/disvalues embedded in their material structure. The bridges over the Long Island parkways constitute a famous example. Langdon Winner (1986) argues that they were intentionally designed with low clearance to prevent buses from passing under them, thus preventing those who did not have private cars - so poor people - and need to use public transportation from accessing the Long Islands nice beaches. Buildings with no access for wheelchairs are equally obvious examples of discrimination embedded in artifacts' structure.

Ad 3. Winner also argues that artifacts have politics, for they change the structure of power in society, and the kind and direction of changes do not depend just on the intentions of those who created a technology. He gives an example of a tomato harvester. Using it allows a farmer to sell tomatoes cheaper than can sell them those who need to employ people. Yet, its use is economically cost-effective only in large areas, so as result, the use of a harvester gives more money and power to those who already own large farms and thereby restructures agriculture. Postman even argues that the advantages and disadvantages of new technologies are never distributed evenly among the population and that every new technology benefits some groups of people and harms others. We may then evaluate the direction of changes caused by technology from a value point of view. The situation becomes even more 
complicated when we add non-human beings into the picture and ask about the influence of new technology on their well-being.

Ad 4. Another argument was developed by David R. Morrow (2013). Using the example of fishing, he shows that technology can also make good people perform harmful activities by increasing the net utility gained from those activities. It is difficult to overfish a large fishery using traditional fishing methods, but it becomes easy with industrial fishing technology. To allow the fish population to regenerate, fishers must cooperate and observe the law restricting the catch. Yet, a technology available to the fishers may change their willingness to cooperate. Disregarding the law and the use of the industrial technology brings huge profits. Thus, new fishing technologies are used not for bad purposes, but but the very existence of that technologies creates a temptation. The problem itself and the irresistible force of temptation constitute a derivative of the application of new fishing technologies not for bad purposes, but only to what they have been invented: for fishing. Users do not need to have blameworthy preferences to make the disappearance of a fish population happen - it is enough that they want to earn a living. Pollution caused by car-using makes another example.

There are more arguments in favor of the value-ladenness of technology, but even the ones sketched above allow us to draw some consequences:

- The existence and proper use of any technology create changes in the material and social/political structure of our world. And those changes may be evaluated from a value point of view.

- The use of technology reshapes our practical and symbolic activities. Thus, technology imposes, makes attractive, or inhibits, or prevents certain actions, and therefore it imposes, facilitates, inhibits, or prevents realization of values;

- Values with which technologies are laden are of different kinds (the thesis of value puralism).

If we admit the above, then not only users but also the designers, producers, marketers, and sellers should be held accountable for the consequences of introducing a certain technology into the world. This in turn means that considering the value-dimension of technology is part of activities of technology development.

\section{RESPONSES TO THE VALUE-LADENNESS OF TECHNOLOGY}

The value-ladenness of technology calls for a systematic and structural response. Let us consider three such responses. The first one is the so-called technology assessment (TA). Functioning a certain technology requires decisions of relevant actors, i.e. those who design and produce, use, and utilize it as well as policy-makers. In order to make decisions in a responsible way they need some "orientation knowledge". TA is to provide such knowledge, i.e a kind of expertise for decision-makers, facing technology value-ladenness and 
possible value-conflicts. TA may be then defined as a field of research which: (1) analyses concerning values - both ex-post and in an anticipatory way technical innovations and their consequences; (2) shows possible alternative paths of development; and (3) makes recommendations to decision-makers. A certain version of TA - called rational technology assessment (RTA) - was developed by Armin Grunwald (1999). Since the development of technology does not automatically lead to human and social progress, and it might even threaten that progress - Grunwald claims - any technology policy is in need of scientific consultation. He however observes, that scientific discussion on how to acquire and establish orientation knowledge for decision-makers is sectoralized in two branches: the ethics of technology, and technology assessment. Ethics stresses the importance of normative implications of policy decisions as well as the importance of moral values and of moral conflicts; Technology Assessment takes a descriptive approach and relies on economic and sociological research. The two branches are based on different assumptions on what constitutes relevant operational knowledge and how it should be obtained. Grunwald sees such a sectoralization as artificial, for two aspects should be included in orientation knowledge: normativity (what should be done) and operationalization (recommendations taking into account how the world really is). In conclusion Grunwald claims that we need an integrated approach which would overcome both normativistic misconceptions (produces norms and recommendations without any connections to societal practices) and naturalistic misconceptions (confusing actual acceptance with normativity). RTA takes a perspective of shaping future, and in this perspective assessing a technology amounts to balancing negative consequences of introducing a certain technology into society and values/goals set for the future. The assessment needs to be done within the normative structure of society which determines a framework for communication and gives criteria of rationality. And the assessment should be a synthesis of some knowledge of facts (cognitive rationality), of recognition of the means-goals relationships (practical rationality), and of the judgment concerning values/goals which a given policy is to serve (evaluative rationality). It seems that ultimately the so-called technology assessment is a kind of a rational judgment from which a recommendation for policy-makers should follow.

Another approach to account for human values in technology is the so-called Value-Sensitive Design (VSD). It starts from a presupposition that artifacts have their intrinsic aim of changing a situation into a better and more desirable one: facilitate an action, make possible what was not possible before, replace humans in dangerous jobs, etc. To achieve the successful incorporation of human values in the design process, VSD employs a tripartite investigation: conceptual, empirical, and technical (Friedman and Hendry, 2019). In the conceptual investigation, one identifies stakeholders (direct and indirect, human and non-human), performs an analysis of how these may be harmed by or benefit from a certain new technology. Additionally, values promoted or 
threatened by producing and using that technology are identified and analyzed. Empirical investigation allows us to determine how stakeholders experience a given technology in relation to the values they consider crucial, what fear and expectations they express with regard to possible consequences of spreading that technology. Technical investigation is to combine insights from the two investigations and consider alternatives of how a technology might be designed to promote the values identified and avoid objections and fears of the stakeholders. Here values conflicts arise and ways of solving them are elaborated. The conceptual, empirical, and technical investigations are interdependent and they inform each other. In this way, technologies become responsive to the call that technology "does good, and avoid evil". Also here the result of investigations should be an evaluative judgment on proposed designs and a recommendation which of them should finally be realized. However, if we recognize that contemporary technologies are systems of material objects and institutions, the spectrum of values that should be considered is broadened, as we need to take into account stakeholders' harms and benefits arising from changes in the institutional setup. Thus, the term "design" should not refer just to a artifact taken in isolation.

Still another approach - called axiometrics of techno-science - is developed by Javier Echeverría (2003) who claims that technological, scientific, and technoscientific activity depends on a complex system of values which includes diverse sub-systems that interact with one another, and whose realization might conflict. He lists ethical, religious, political, epistemological, economic, juridical, ecological, technological, and military values. Echeverría develops a formal axiological framework to evaluate decisions and activities within that realm. He introduces a distinction between nuclear and orbital values as well as the classification of values following axiometrical criteria based on the notion of the gradual satisfaction of a plurality of values. The scales of measurement suggested should allow for a certain quantification of degrees of satisfaction related to the diverse values. Many of the values mentioned cannot be measured on a common scale but only on ordinal or cardinal scales. Technoscience - Echeverría claims - is an activity that is not only describing or explaining the world, but is transforming it. The values brought forth from the good and bad of techno-systems always depend on previously developed values that allow an evaluation of these techno-systems in the first place.

The three approaches to deal with the value-ladenness of technology are compatible with typical systems engineering approaches (e.g., the waterfall model and the spiral model). Yet, they suffer from a major deficiency: the lack of an established and accepted fundamental theoretical grounding (Boztebe, 2003; Lekka-Kowalik, 2018) and a comprehensive list of values (Borning and Muller, 2012).

\section{A SEARCH FOR AN AXIOLOGICAL FRAMEWORK}

There is a general agreement that any model for dealing with the value- 
ladenness of technology should allow for making rational decisions - rational judgments on how to make technology efficiently working and at the same time values respected. Such a judgment may then be passed to policy-makers and other stakeholders. How can we interpret that judgment? We may see it as an optimalization judgment. According to Agazzi (2004), one arrives at such a judgment by dialectical comparison and balancing of various possible decisions and values. Yet, two problems here arise. First, optimalization judgments might vary from one expert group to another. We need then either an algorithmic procedure for balancing values - as Echeverría suggests to build - or we may decide to have just one group of experts for each particular decision to be made in technology policy and for all stakeholders. This brings the question of who should choose those experts? There is an answer to this problem: participation of stakeholders in backcasting and therefore also in passing an optimalization judgment on a given technology policy. Jaco Quist and Philip Vergragt (2006) suggest that approach. Also VSD model includes the value views of direct and indirect stakeholders. The optimalization judgment would then be a result of negotiation. Here we have to assume that all values are negotiable, including moral values, what is a controversial assumption. Moreover, the justification of such an optimalization judgement in fact boils down to a kind of persuation - we negotiate a judgment with relevant parties but this procedure does not guarantee that this is a right judgment, even if it is accepted by the parties. It, of course, takes into account the interests of parties involved but there is no procedure to secure that all parties affected by the decision are invited to negotiations. This in turn elucidates a deeper problem: we know from historical experience that not everything what people hold as values are real values. Such a problem does not arise only if we accept that current value views in a given society are true by convention. Thus, the understanding of a judgment on technology as an optimalization judgment works only if we assume that values are conventional, and agree that all types of values can be compromised in the process of balancing goals against negative consequences of technological development.

We may also interpret the evaluative judgement on technology as an if-then judgment. This may take two forms. In one it will be a quasi-deductive reasoning: if the normative structure of a given society is such and such, then it follows that a given technology should be so and so evaluated and such and such developmental policy accepted. Here both the normative structure of a given society and the goals are accepted as "given". For the "given" goals within a normative structure alternative technology policies can be elaborated. Yet, this is against the value-ladenness of technology, because it makes the technology neutral in itself and its ladenness occurs only in the eyes of a particular society. e face here a problem that different societies may have different normative structures, and therefore recommended policies might be different. Thus, evaluative judgments on technology - and therefore also recommendations might have only a local character. However, the development and use of 
technology has a global impact, so policies in one society in fact influence the state of societies with different policies. So more powerful society would influence other societies. In a more sophisticated version of a debate on valuejudgements concerning technology, when those judgements are treated as ifthen judgments, we could elaborate conflicting views as coherent valuepositions disclosing their ultimate value-axioms, deduce "consequences" from particular value-positions in terms of evaluative attitudes, ascertain consequences that would necessarily follow from practical realization of a particular evaluative attitude to a given technology because of certain unavoidable means must be used, and that certain inevitable, but not intended, side-effects must be expected. This is purely empirical inquiry, but it indirectly influenced the value-position, because it might show that (a) the intended goal (value-postulate) is not realizable, because there are no means to achieve it; (b) that the realization would be more or less illusory, for there would occur unintended side-effects that would frustrated the plan; (c) that certain means and side-effects should be considered. Such a debate would certainly be valuable and helpful, but it would not establish which of described normative structures should be accepted and how to solve value conflicts. The debate would result in a spectrum of possibilities. Yet, someone has to decide as to which design should be followed, whether that technology should be produced on a large scale, who should have access to it, etc. The issue of power relations in the technology development would here reemerge.

Thus, if we accept the value-ladenness of technology and the need to pass an evaluative judgment on technology (in fact at any stage of its development), we need an axiological frameworkin which the issue of values and their status is not reduced to a normative framework accepted by a given society and in which judgments about values are seen as true/false. David G. Hendry and others (2021) rightly claim that we need a formative framework that bounds and guides processes of technology development. I apply their view generally to any model of dealing with the value-ladenness of technology, even if originally it referred only to value-sensitive design. Formative frameworks differ in purpose from prescriptive ones, which prescribe that certain steps be followed to frame a problem and to arrive at a solution, and from descriptive frameworks, which describe the practices involved in the process of technology development. Thus, it must be a framework that forms people capable of arriving and decisions and rationally justifying them. No rigid procedures are prescribed - the sequence of considerations and actions is left up to the stakeholders. Working within that framework requires to be sensitive to values in the full complexity of the situation and to seek good overall solutions, not perfect ones. And such a framework lends itself to creative application in most, in not all cases, of technology. Also it is open to revision. With this flexibility there come opportunity and responsibility. The authors attempt to show how to build such a framework by distinguishing three types of design knowledge-know-about (theory), know-that (translation), and know-how (method) and elaborating their interrelationships. The crucial 
step is theoretical: well-chosen abstractions, propositions or perspectives, carefully defined and explicated for considering concrete situations. They are distilled from the philosophical, social science, and technical literature, and informed by practical experience and characterize which values are implicated in a given stage. Yet, there is a basic problem: there are many views, especially philosophical ones, on what values are, what hierarchy (if any) they constitute, and on how value-judgments can be justified. Providing justification is the basic requirement of human rationality which ultimately depends on the choice of a philosophy, and arguably, a social science paradigm.

Shadi Kheirandish and others (2020) made an attempt to avoid that problem and build such a framework by empirically investigating how different people group human values. By spreading the link of the Human Values Survey worldwide via the internet, they had participants with different cultural backgrounds and on that basis they distinguish 9 groups of values (carefulness, justice, ecology, respect for others, meaningfulness, status, pleasure, respect for oneself and personal development) with some specification in each group (42 key values, and 135 extra values). Yet, this framework is not comprehensive (dignity is not mentioned) and it does not indicate how to balance the values in the case of a conflict. Moreover, all grups of values are treated as equally important, what is certainly not the case in real life. The problem is however even more serious: the framework is built on the basis of what values people accept, but values declared are not necessarily true values. Thus, when building such a framework we need to show what true values are at stake and how to evaluate the importance of values in concrete situations as well as distinguish those values which can be compromised from those which must not. Moreover, justification must be provided for each of those steps. This in turn suggests that the understanding of values (axiology) must be nested in the understanding of the human person and her relationship to society (anthropology). The question of a framework in which the analysis of technology with respect to values is even more primary than the issue of a methodology for carrying on such analysis, even if the lack of a consistent methodology is also a problem (Michalski 2019). So the need of integrating a sociological approach and a philosophical approach becomes vivid. In this point a question of which philosophy and which sociological paradigm should be chosen. We should also bring into the process of building a framework also other scholarly domains (including the humanities) as well as non-scientific expertise. In this sense such a framework would be a result of transdisciplinary research.

\section{CONCLUSIONS}

The thesis of the value-ladenness of technology is now quite generally recognized and various responses to this fact are developed. Their starting point is the pluralism of values involved. In the paper three such responses are analyzed: technology assessment, value-sensitive design, and the axiology of techno-science. Yet, they all suffer from the same deficiency. We need a 
framework which would be formative for policy-makers, engineers, and other stakeholders in the technology development, but so far any existing proposal of such a framework does not allow for distinguishing actually held views in a given society from real values, does not show how to solve value conflicts, does not show how to evaluate the degree of importance of values, and therefore does not allow to provide satisfactory rational justification of decisions in the realm of technology development. Friedman and others (2021) indicated eight grand challenges for value-sensitive design. I claim that those challenges are valid for any model of technological develpment we build in response to the valueladenness of technology. To face those challenges we need a formative framework. To build such a framework is the grandest challenge for the development of value-laden technology. Of course, any such framework does not guarantee that we would not be mistaken in our cognition of facts and values, choice of means, etc. It does not also quarantee that new fact and new values do not occur. So, we have to assume a reformulation of a framework along with passing evaluative judgments on technology. The need of building a formative value framework leads also to a more general conclusion: there are such human undertakings in which the usual division between philosophy, natural science, social sciences, and the humanities does not work. Responding to the valueladenness of technology is one of them.

\section{ACKNOWLEDGEMENTS}

The research for this paper was done as part of the project funded by the Minister of Science and Higher Education within the program under the name "Regional Initiative of Excellence" in 2019-2022, project number: 028/RID/2018/19.

\section{REFERENCES}

Agazzi, E. (2004). Right, Wrong and Science. The Ethical Dimensions of the TechnoScientific Enterprise. Amsterdam-New York: Rodopi.

Borning, A. and Muller, M. (2012). Next steps for value sensitive design. Available at: https://www.researchgate.net/publication/241623219_Next_Steps_for_Value_Se nsitive_Design [Accessed 5 June 2021].

Boztepe, S. (2003). The notion of value and design. Available at: https://www.researchgate.net/publication/228472368_The_notion_of_value_and _design [Accessed 4 June 2021].

Echeverria, J. (2003). Science, Technology, and Values: Towards an Axiological Analysis of Techno-scientific Activity. Technology in Society, 25, pp. 205-215.

Friedman, B. and Hendry, D. G. (2019). Value Sensitive Design: Shaping Technology with Moral Imagination. Cambridge, MA: MIT Press.

Friedman, B., Harbers, M., Hendry D.G., Hoven van den, J., Jonker, C., and Logler, N. (2021). Eight Grand Challenges for Value Sensitive Design. Ethics and Information Technology 23, pp. 5-16.

Grunwald, A. (1999). Technology Assessment or Ethics of Technology. Ethical Perspectives, 6, pp. 170-181.

Hendry, DG. Friedman, B. and Ballard S. (2021). Value sensitive design as a formative framework. Ethics and Information Technology, 23, pp. 39-44. Kheirandish, S., Funk, M., Wensveen, S., Verkerk, M., and Rauterberg, M (2020). A Comprehensive Value Framework for Design. Available at: https://www.researchgate.net/publication/342390965_A_comprehensive_value_ 
framework_for_design [Accessed 2 June 2021].

Lekka-Kowalik, A. (2018). Rational technology assessment in need of a philosophical framework, Zeszyty Naukowe Politechniki Śląskiej. Organizacja i Zarządzanie, 115, pp. 219-231.

Lekka-Kowalik, A. (2005). Democracy and the Autonomy of Individuals in the Global Information Infrastructure. In: M.M. Żydowo, ed., Ethical Problems in the Rapid Advancement of Science. Warszawa: Polish Academy of Sciences, 2005, pp. 3345.

Lizut, R. (2014), Technika a wartości. Spór o aksjologiczną neutralność artefaktów. Lublin: Wydawnictwo Naukowe Academicon.

Maslow, H. (1966). The Psychology of Science. New York: Harper \& Row.

Michalski, K (2019). Technology Assessment. Ocena technologii - nowe wyzwania dla filozofii nauki i ogólnej metodologii nauk. Rzeszów: Oficyna Wydawnicza Politechniki Rzeszowskiej.

Morrow, D.R. (2013). When Technologies Make Good People Do Bad Things: Another Argument Against the Value-Neutrality of Technologies, Science and Engineering Ethics, 20(2), pp. 1-15.

Postman, N. (1998). Five Things We Need to Know About Technological Change. Available https://www.cs.ucdavis.edu/ rogaway/classes/188/materials/postman.pdf [Accessed 5 June 2021].

Quista, J and Vergragt, Ph. (2006). Past and future of backcasting: The Shift to Stakeholder Participation and a Proposal for a Methodological Framework, Futures 38, pp. 1027-1045.

Winner L. (1986), The Whale and the Reactor. A Search form Limits in an Age of High Technology. Chicago: The University of Chicago Press.

\begin{abstract}
The idea that technology is only a value-neutral instrument that can be used for good and bad purposes is not tenable anymore. Technology shapes our human life in all its dimensions and determines the direction of social changes. In the paper, I first show a few arguments in favor of the value-ladenness of technology and then approaches developed in response to that fact. I will argue that none of those responses is satisfactory, for they lack a formative value framework that would serve for decisions and their justification in the realm of technology development. Building such a framework requires a transdisciplinary and cooperative effort.
\end{abstract}

Keywords: value-ladenness of technology, technology assessment, value sensitive design, axiometrics, formative value framework 